Prepared for

United States Department of Energy

Office of Energy Research

Office of Basic Energy Sciences

Carbon Dioxide Research Division

Washington, D.C. 20545

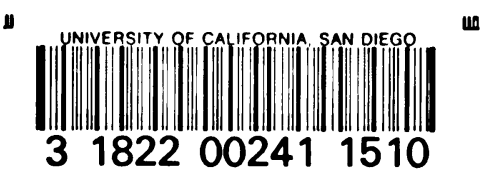

DOE/ER/60397-H2

Dist. Category UC-11

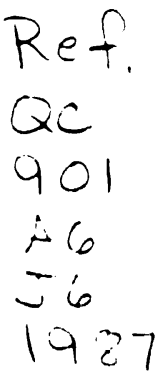

SIC

\title{
A Data Bank of Antarctic Surface Temperature and Pressure Data
}

Prepared by:

P.D. Jones

Climatic Research Unit

University of East Anglia

Norwich, U.K.

and

D.W.S. Limbert

British Antarctic Survey

Madingley Road

Cambridge, U.K.

Under Contract No. DE-FG02-86ER60397 